\title{
Identification of urine biomarkers associated with lung adenocarcinoma
}

\author{
Weiwei Wang ${ }^{1, *}$, Shanshan Wang ${ }^{1, *}$ and Man Zhang ${ }^{2,3}$ \\ ${ }^{1}$ Department of Pulmonary and Critical Care Medicine, Beijing Shijitan Hospital, Capital Medical University, Beijing, China \\ ${ }^{2}$ Clinical Laboratory Medicine, Beijing Shijitan Hospital, Capital Medical University, Beijing, China \\ ${ }^{3}$ Beijing Key Laboratory of Urinary Cellular Molecular Diagnostics, Beijing, China \\ *These authors have contributed equally to this work \\ Correspondence to: Man Zhang, email: mzhang99@aliyun.com \\ Keywords: urine peptides, lung adenocarcinoma, MALDI-TOF MS, immunohistochemistry, biomarker \\ Received: November 30, $2016 \quad$ Accepted: January 24, $2017 \quad$ Published: March 03, 2017 \\ Copyright: Wang et al. This is an open-access article distributed under the terms of the Creative Commons Attribution License (CC-BY), \\ which permits unrestricted use, distribution, and reproduction in any medium, provided the original author and source are credited.
}

\section{ABSTRACT}

Lung adenocarcinoma (LAC) progression is accompanied by changes in protein levels that may be reflected in body fluids, such as urine. Urine collected from LAC patients $(n=34)$ and healthy controls $(n=36)$ was analyzed via matrixassisted laser desorption/ionization time-of-flight mass spectrometry (MALDI-TOFMS) combined with weak cationic exchange magnetic beads. The results revealed 76 urinary polypeptides significantly different between LAC patients and normal controls $(P<0.05)$. Twenty-two of these peptides were up-regulated and 54 were down-regulated. Thirteen peptides had average peak intensities $>600$. Twelve of these 13 peptides were successfully identified using nano-liquid chromatographytandem MS. Receiver operating characteristic analyses identified seven peptides with superior LAC diagnostic performances. Immunohistochemical staining in 20 paired LAC and adjacent normal tissues showed that IGKC, AAT, SH3BGRL3, osteopontin and gelsolin levels were higher in LAC tissues than in adjacent tissuesand were closely associated with LAC. Urinary peptides assessments may thus provide a novel, noninvasive, repeatable method for detecting and monitoring LAC. New, low-cost detection methods and bioinformatics tools are therefore urgently needed for the analysis of low abundance proteins and peptides in body fluids.

\section{INTRODUCTION}

Lung cancer is one of most commonly diagnosed cancers and the leading cause of cancer death worldwide [1]. Lung adenocarcinoma (LAC) is the most common form of lung cancer, and constitutes nearly $40 \%$ of all lung cancer cases [2]. Lung cancer prognosis remains poor, and the 5 -year survival rate of approximately $18 \%$ has not improved over several decades [1]. This is primarily due to late stage detection and a paucity of therapies effective against metastatic disease. Timely detection of lung cancer is hampered by several factors. First, there are no specific clinical symptoms in the early-stage of the disease. Second, aggressive therapeutic intervention is hampered by a relatively high median patient age [3]. Third, lowdose spiral computed tomography (LDCT) is unsuitable for widespread screening due to high costs and false positive rates. Moreover radiation exposure may increase the risk of lung cancer [4]. Finally, no accurate and reliable lung cancer biomarkers have been identified to date.

Protein expression and release differs between normal and cancer cells. Breakdown of large proteins often involves proteolytic processing, and progression to malignancy is often accompanied by changes in protease activities. Some cancer-specific peptides can be captured and analyzed to ascertain tumor status in vivo, and identification of such peptides might facilitate the development of biomarkers for early detection of lung cancer. Peripheral biofluids, such as serum and bronchoalveolar lavage fluid (BALF) have been used to detect lung cancer [5]. Recently, urine has attracted increased attention as a biospecimen because it 
remains relatively stable due to minimal post-sampling proteolysis. Urinalysis is non-invasive and urine is frequently accessible at large volumes without laborintensive sample preparation. Urine markers may be clinically useful in diagnosing and monitoring bladder and prostate cancers [6-8]. Diagnostic tests based on urine polypeptides or protein markers can reportedly differentiate cholangiocarcinoma from benign biliary disorders, and may replace bile fluid analyses [9]. Tomasz et al. established a novel, three-protein biomarker panel to detect early-stage pancreatic cancer via urine [10]. Still, urine is seldom analyzed in the hunt for LAC biomarkers.

The peptidome, or the low-molecular-weight protein fragments and peptides in urine, represents an emerging tool for biomarker discovery. In recent years, mass spectrometry (MS) -based serum peptide screening has been used as a high-throughput approach to identify potential diagnostic and prognostic biomarkers for various diseases [11]. For instance, magnetic bead-based matrix assisted laser desorption/ionization time-of-flight mass spectrometry (MB-based MALDI-TOF-MS) technology was used to identify serum peptide fingerprints in esophageal squamous cell carcinoma [12]. Detection of low abundance proteins is possible, and quantitative information can be obtained from the spectral counts. However, urine peptidome studies in lung cancer have not simultaneously evaluated candidate biomarkers in patient tumor tissue [13].

In this study, we detected proteomic changes in urine samples from 70 LAC and control samples. Urine peptides were purified using weak cation-exchange magnetic beads (WCX-MB),. MALDI-TOF-MS was used to analyze peptide expression profiles. Candidate diagnostic peptides were then identified by nanoliquid chromatography-tandem MS,. and were further verified using immunohistochemical staining in tissue sample sets. Our results indicated that specific urinary peptides were closely associated with LAC. The identified peptides might serve as potential biomarkers to noninvasively detect LAC, through analysis of urine samples.

\section{RESULTS}

\section{Urinary peptidome profiling}

Urine samples from 70 volunteers were purified using magnetic beads and exhibited spectral peaks in the

A

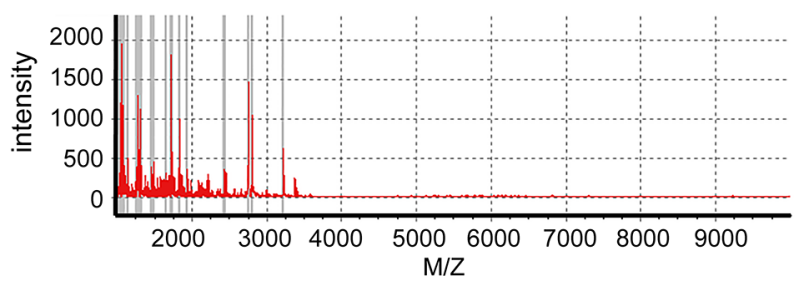

range of 1000-10,000 Da. Typical WCX representative spectra for LAC and normal control patient samples following MALDI-TOF MS analysis are shown in Figure 1. Peak position and peak intensity differences were observed between the two groups.

\section{Peptide screening}

MALDI-TOF analysis detected a total of 94 peaks with $\mathrm{m} / \mathrm{z}$ spectra ranging from 1000 to 10,000 Da. Seventy-six out of 94 features differed between LAC patients and normal controls $(P<0.05)$ (Figure 2$)$. Among these, 22 peptides were upregulated and 54 were downregulated in LAC patients compared to controls. Thirteen peptide peaks had average intensities $>600$ in the LAC or normal control groups. The mass-to-charge ratios of these peaks were: 1053.1, 1490.9, 1280.1, 1085, 1258.8, 1069.1, 1306.1, 1719.5, 1736.6, 1833.4, 2756.6, 1097.8, and 1296.2 (Figure 3). Compared to normal control, six peptides (m/z 1053.1, 1490.9, 1280.1, 1085, 1258.8, and 1069.1) were upregulated in LAC patients (Figure 4A, Table 1) while five (m/z 1306.1, 1719.5, 1736.6, 1833.4, and 2756.6) were downregulated (Figure 4B, Table 1). Two peptides (m/z 1097.8 and 1296.2) were the same between LAC patients and normal controls (Table 1, $P>0.05$ ).

\section{ROC analysis}

For the thirteen peptides with average peak intensities $>600$, ROC analyses were performed to calculate the sensitivities, specificities and accuracies at different cut-off points. For the ROC curves, the AUCs of $\mathrm{m} / \mathrm{z} 1053.1,1258.8$ and 1490.9 were 0.81 (95\% CI $0.67-$ $0.91 ; P<0.0001$ ), 0.83 (95\% CI 0.73-0.92; $P<0.0001$ ) and 0.80 (95\% CI 0.68-0.90; $P<0.0001)$, respectively. Sensitivities and specificities were $62 \%$ and $92 \%$ for $\mathrm{m} / \mathrm{z}$ $1053.1,77 \%$ and $78 \%$ for $\mathrm{m} / \mathrm{z} 1258.8$, and $79 \%$ and $81 \%$ for $\mathrm{m} / \mathrm{z} 1490.9$. These three peptides were upregulated in the LAC group. The AUCs of $\mathrm{m} / \mathrm{z} 1306.1,1719.5,1833.4$ and 2756.6 were 0.80 (95\% CI $0.69-0.90 ; P<0.0001)$, 0.84 (95\% CI $0.74-0.93 ; P<0.0001), 0.86$ (95\% CI $0.77-$ $0.94 ; P<0.0001$ ), and 0.82 (95\% CI 0.72-0.92; $P<0.0001$ ), respectively. Sensitivities and specificities were $68 \%$

B

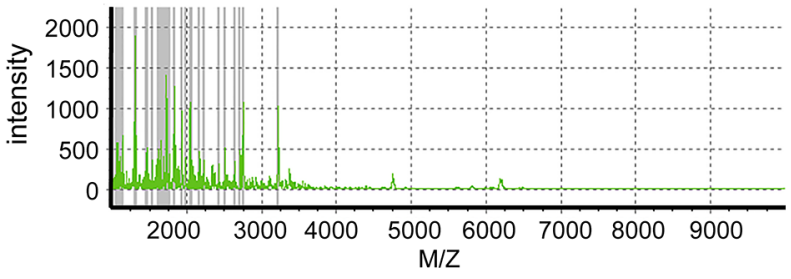

Figure 1: Urine peptide fingerprints in the range of $\mathbf{1 0 0 0 - 1 0 , 0 0 0 ~} \mathbf{~ m} / \mathbf{z}$. Mass spectra of A. lung adenocarcinoma (red, $\mathrm{n}=23$ ) and B. normal controls (green, $\mathrm{n}=16$ ) created by ClinTOF. 
and $83 \%$ for $\mathrm{m} / \mathrm{z} 1306.1,91 \%$ and $67 \%$ for $\mathrm{m} / \mathrm{z} 1719.5$, $74 \%$ and $89 \%$ for $\mathrm{m} / \mathrm{z} 1833.4$, and $77 \%$ and $83 \%$ for $\mathrm{m} / \mathrm{z}$ 2756.6. These four peptides were downregulated in the LAC group. Peptides with $\mathrm{m} / \mathrm{z} 1280.1,1069.1,1085$, and 1736.6 had limited clinical utility, with AUCs of 0.73 (95\% CI 0.61-0.85; $P=0.001), 0.70$ (95\% CI 0.57-0.83; $P=0.004), 0.64$ (95\% CI $0.51-0.77 ; P=0.043)$ and 0.79 (95\% CI 0.67-0.90; $P<0.0001$ ), respectively. Sensitivities and specificities were $50 \%$ and $89 \%$ for $\mathrm{m} / \mathrm{z} 1280.1,85 \%$ and $61 \%$ for $\mathrm{m} / \mathrm{z} 1069.1,85 \%$ and $42 \%$ for $\mathrm{m} / \mathrm{z} 1085$, and $74 \%$ and $81 \%$ for $\mathrm{m} / \mathrm{z} 1736.6$. Peptides with $\mathrm{m} / \mathrm{z} 1280.1$, 1069.1, and 1085 were upregulated in the LAC group, while the peptide with $\mathrm{m} / \mathrm{z} 1736.6$ was downregulated (Figure 5).

\section{Biomarkers identification}

Peptides sequencing via nano-liquid chromatography-tandem MS successfully identified 12 out of 13 peaks with average intensities $>600$. The Mascot search of the Uniprot-SwissProt Human database provided protein name. The $\mathrm{m} / \mathrm{z} 1069.1$ peak sequence was not identified. Detailed identification results are shown in Table 2.

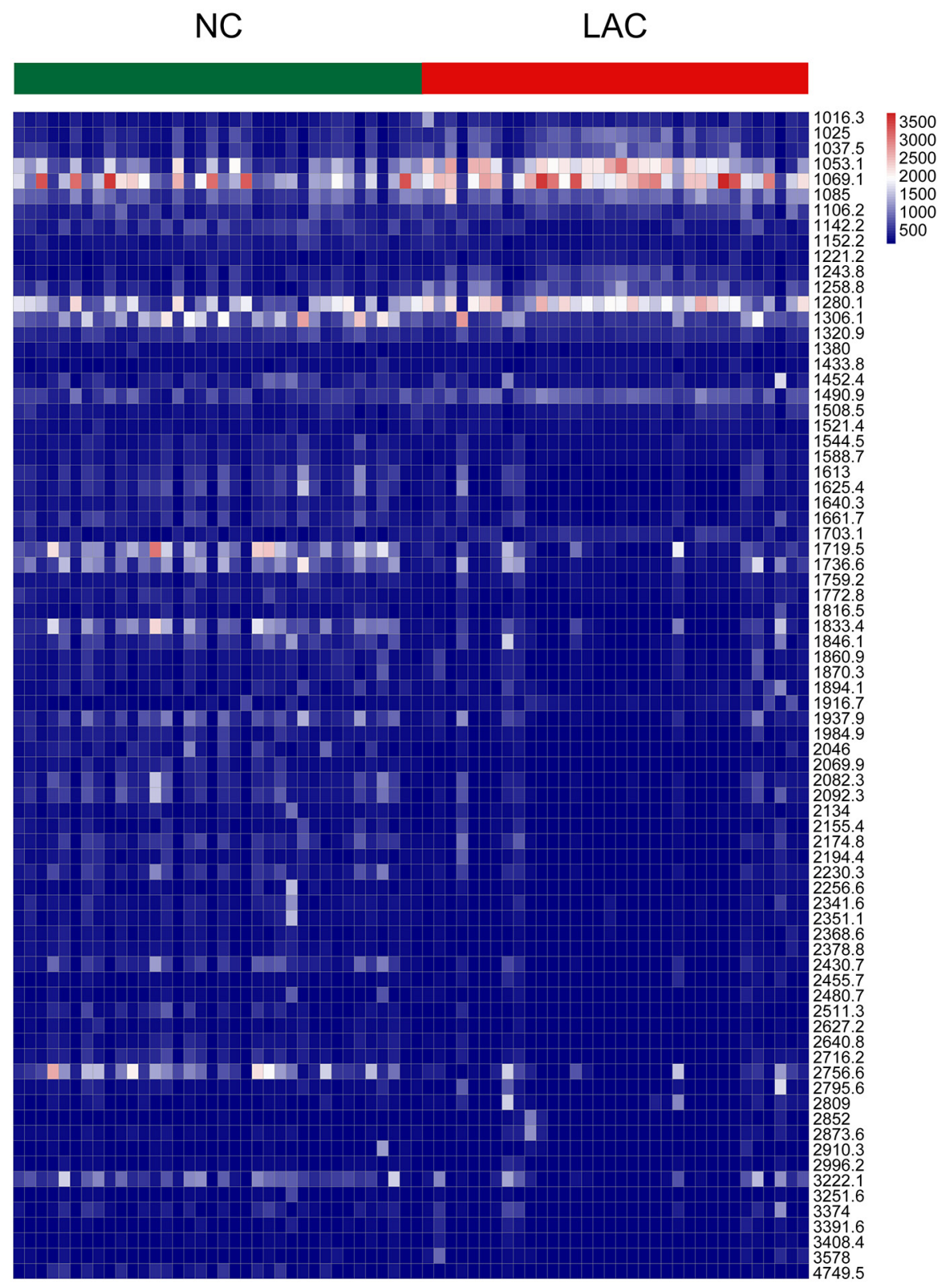

Figure 2: Columns represented samples, rows were $\mathrm{m} / \mathrm{z}$ peaks (in numerical order), the heat map scales of peak intensities range from blue to red with the transitional midpoint on white. 


\section{IGKC, AAT, SH3BGRL3, osteopontin, gelsolin, cystatin-A and LMAN2 expression in LAC}

Immunohistochemistry was employed to assess IGKC, AAT, SH3BGRL3, osteopontin, gelsolin, cystatin-A and LMAN2 levels in 20 paired LAC and adjacent normal tissues. Staining was primarily observed in the cytoplasm. IGKC, AAT, SH3BGRL3, osteopontin and gelsolin levels were increased in LAC tissues compared to controls $(P<0.05$; Figure 6 , Table 3$)$. There were no cystain-A or LMAN2 expression differences between LAC tissues and controls $(P>0.05)$.

\section{DISCUSSION}

Urine as an analytical body fluid has several advantages over blood. Urine collection is noninvasive and can be repeated to obtain sufficient sample quantities at multiple time points. Urine proteins are also relatively stable due to low levels of proteolytic degradation. Furthermore, urine harbors lower numbers of polypeptides and proteins as compared to other body fluids, and has a lower dynamic range of protein concentrations. Blood, on the other hand, contains 20 kinds of high abundance proteins which correspond to $99 \%$ of the proteins in the sample; these high abundance proteins mask other less abundant, potentially clinically usefulproteins [14].
More than 2,300 different proteins have been detected in urine [15]. Proteomic analyses of urine suggest that it contains information specific to a number of kidney diseases, as well as cardiovascular and brain diseases, and certain types of cancer [16]. Here, we successfully established a peptide marker panel based on urinary peptides that appear to reflect LAC progression.

We used WCX-MB coupled with MALDI-TOF-MS to analyze human urine peptidomes, and distinguished LAC-specific proteinaceous biomarkers present in urine. We successfully identified and validated a portion of these biomarkers, and developed a urine-based LAC diagnostic test. To the best of our knowledge, this was the first assessment of potential LAC biomarkers in human urine using WCX coupled with MALDI-TOFMS. These biomarkers might be used to monitor patients at high risk for LAC. Seventy-six $\mathrm{m} / \mathrm{z}$ peaks differed between LAC patients and normal controls. Six of these peaks $(\mathrm{m} / \mathrm{z} 1053.1,1490.9,1280.1,1085,1258.8$ and 1069.1) were upregulated in LAC with peak intensities $>600$. These peptides were identified as Ig kappa chain $\mathrm{C}$ region (IGKC), alpha-1-antitrypsin (AAT), IGKV2-28, Ig kappa chain V-IV region Len, SH3 domain-binding glutamic acid-rich-like protein 3 (SH3BGRL3). We hypothesized that upregulated proteins in lung cancer patient urine are most likely derived from cancer cells. Immunohistochemistry results in 20 surgically resected

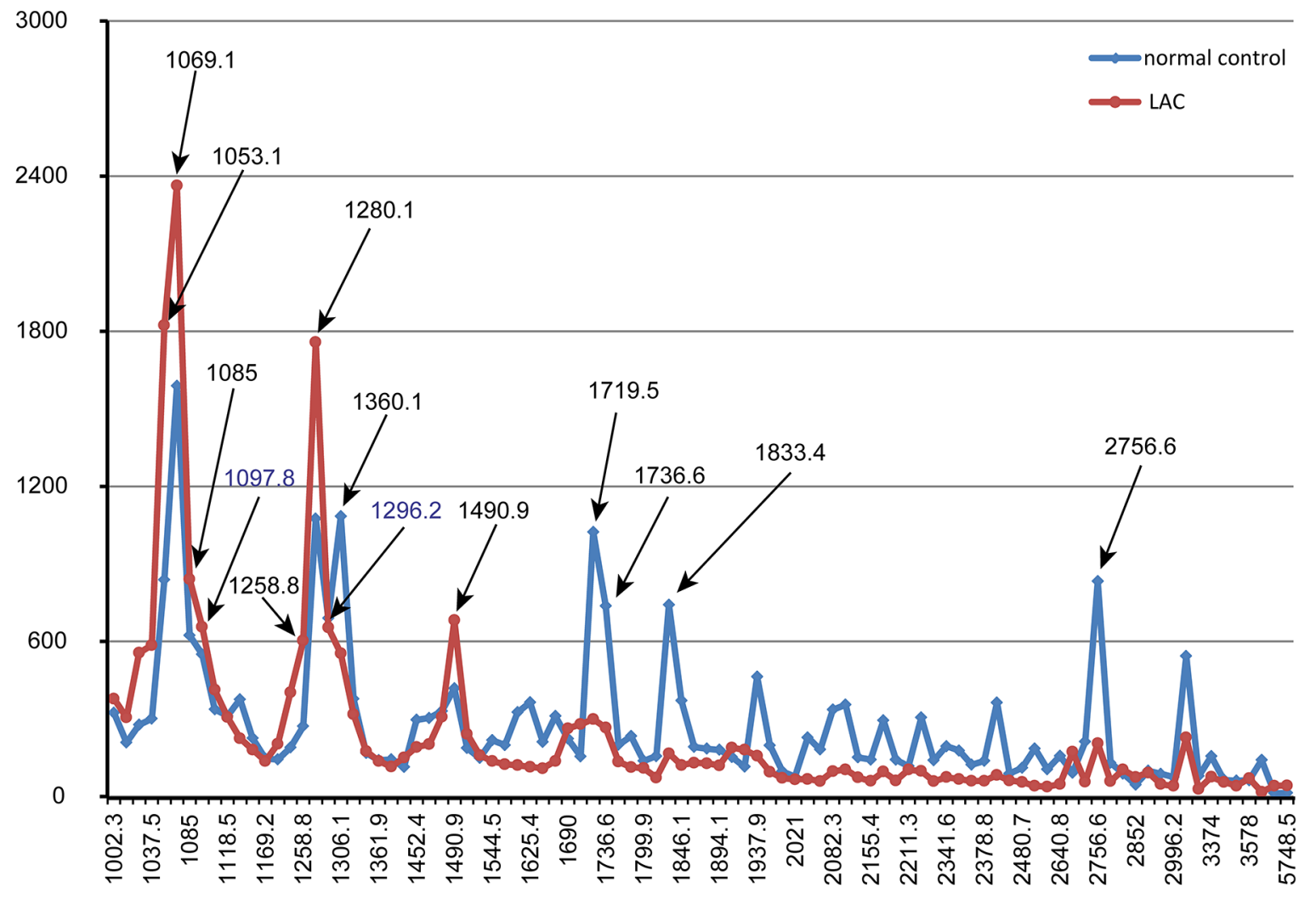

Figure 3: The distribution of average peak area from two groups and arrows indicated peaks that average intensity was higher than 600 in LAC group or normal control. 
LACs and adjacent normal tissues showed that IGKC, AAT and SH3BGRL3 were more highly expressed in tumor cells as compared to non-tumor tissues. These proteins might play a role inLAC development.
Five peptides (m/z 1306.1, 1719.5, 1736.6, 1833.4 and 2756.6) were down-regulated in LAC patients, with peak intensities $>600$ in normal controls. The downregulated peptide, $\mathrm{m} / \mathrm{z}$ 1306.1, and the upregulated

A
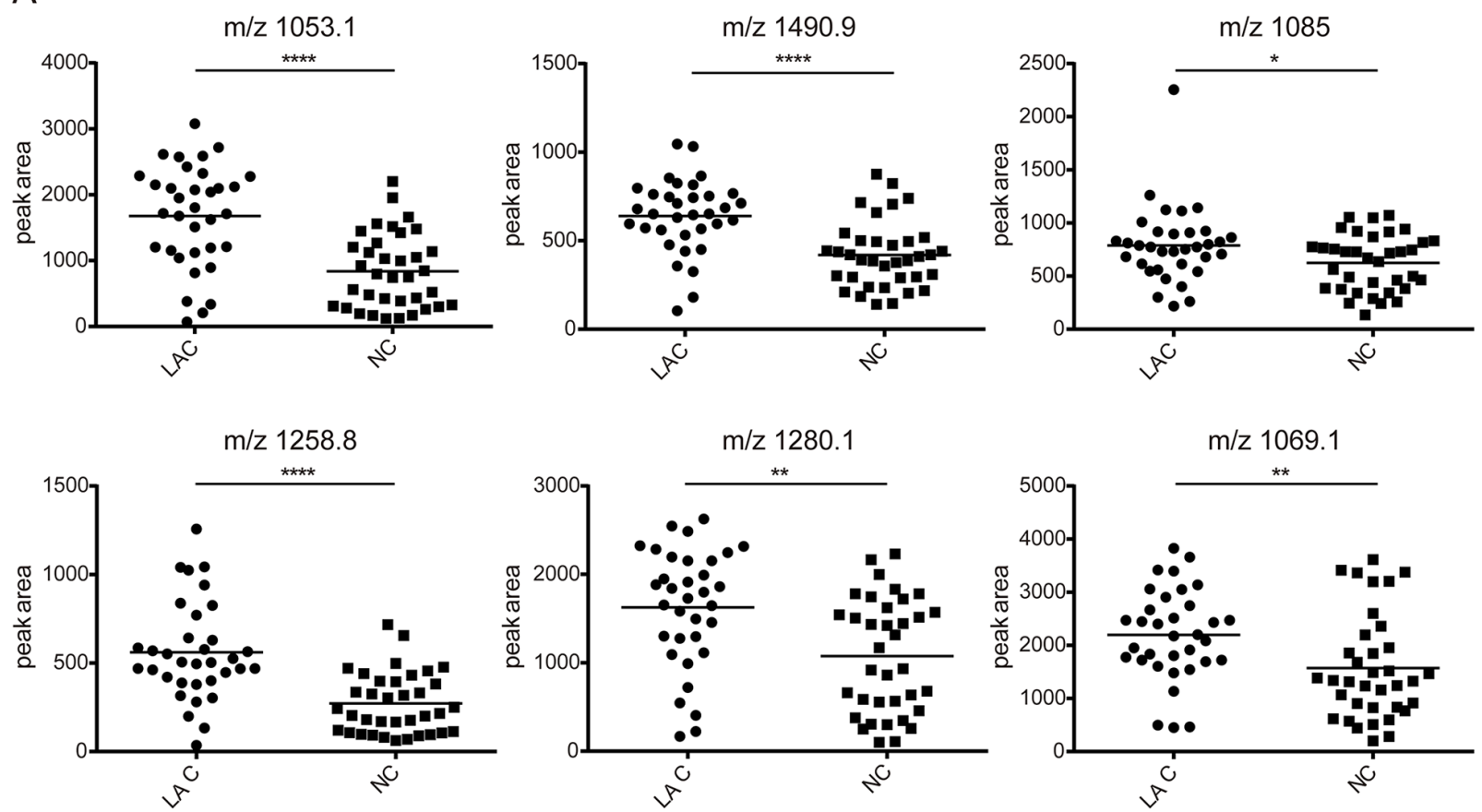

B
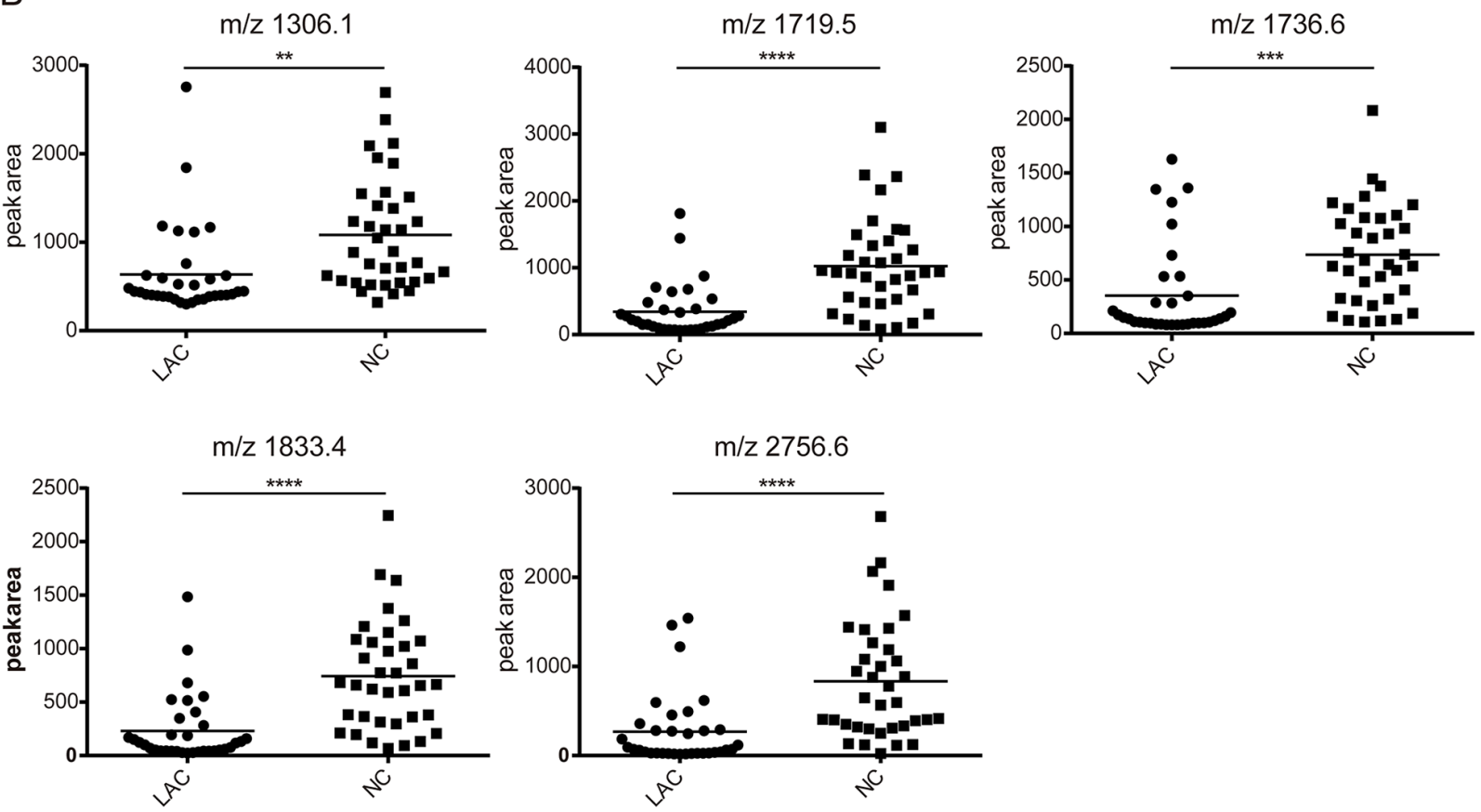

Figure 4: The feature of the 11 selected peaks in lung adenocarcinoma and health control. The peak area distributions in all samples. A. The average value showing an increasing trend in lung adenocarcinoma group compared with normal control group. B. The average value showing a decreasing trend in lung adenocarcinoma group compared with normal control group. ${ }^{*} P<0.05, * * P<0.01$, $* * * P<0.001$, **** $P<0.0001$. 
Table 1: The characteristic of thirteen selected peaks

\begin{tabular}{lccc}
\hline Peptides peaks $(\mathbf{m} / \mathbf{z})$ & $\boldsymbol{P}$ value & Cancer group & Control group \\
\hline 1053.1 & $<0.0001$ & $1679.8 \pm 772.5$ & $839.0 \pm 564.7$ \\
1490.9 & $<0.0001$ & $639.4 \pm 205.7$ & $418.9 \pm 187.9$ \\
1085 & 0.0430 & $789.4 \pm 356.7$ & $623.1 \pm 263.3$ \\
1258.8 & $<0.0001$ & $560.5 \pm 273.8$ & $271.6 \pm 171.2$ \\
1280.1 & 0.0010 & $1625.4 \pm 666.8$ & $1075.3 \pm 646.1$ \\
1069.1 & 0.0080 & $2196.6 \pm 856.3$ & $1588.5 \pm 983.0$ \\
1306.1 & 0.0010 & $637.2 \pm 503.1$ & $1083.9 \pm 620.7$ \\
1719.5 & $<0.0001$ & $343.2 \pm 390.7$ & $1023.7 \pm 700.8$ \\
1736.6 & 0.0010 & $352.3 \pm 439.5$ & $737.1 \pm 462.4$ \\
1833.4 & $<0.000$ & $230.7 \pm 315.4$ & $742.0 \pm 508.0$ \\
2756.6 & $<0.000$ & $269.5 \pm 401.6$ & $832.6 \pm 662.1$ \\
1097.8 & 0.2720 & $616.3 \pm 248.2$ & $550.0 \pm 252.2$ \\
1296.2 & 0.7530 & $663.9 \pm 293.2$ & $689.5 \pm 378.0$ \\
\hline
\end{tabular}

The peak area of every peak in two groups was presented as mean $\pm \mathrm{SD}$. $P$ value was calculated by $t$-test (normally distributed continuous data) or Mann-Whiney $U$-test (non-normally distributed continuous data). $P<0.05$ was considered as statistically significant difference.

peptide, $\mathrm{m} / \mathrm{z}$ 1490.9, were different fragments of AAT. The downregulated peptide, $\mathrm{m} / \mathrm{z} 1719.5$, and the upregulated peptide, $\mathrm{m} / \mathrm{z} 1085$, were different fragments of SH3BGRL3. The downregulated peptide, $\mathrm{m} / \mathrm{z} 2756.6$, and the peptide, $\mathrm{m} / \mathrm{z} 1097.8$, were different fragments of gelsolin. The surprising finding that different fragments of the same protein were differentially expressed in LAC vs normal tissuess will be explored in future work.

The peaks, m/z 1736.6 and 1833.4, were identified as cystatin-A and osteopontin. Consistent with previous studies, gelsolin and osteopontin exhibited higher expression in LAC tissues than adjacent normal tissues [17-19]. These proteins were elevated in blood and play important roles in tumor progression and metastasis $[20,21]$, but both were downregulated in LAC patient urine samples. This indicated that the formation of urine peptides is a complex process that necessitates further study.

We found, unexpectedly, that LAC patients urine samples contain elevated levels of some immunoglobulin (Ig) light chains, such as IGKC, Ig kappa chain V-IV region Len, protein IGKV2-28 and Ig lambda-2 chain $\mathrm{C}$ regions. It is generally accepted that under normal conditions, mature B lymphocytes are the sole source of immunoglobulins. This elevated antibody levels are likely induced by a disordered immune system. Based on our findings, IGKC may arise from cancer cells themselves. Previous studies confirmed Ig expression in many nonhematopoietic cancer cells, including breast, colon, lung, liver, cervical and oral cancers. Human epithelial cancer produces IgG in both cytoplasmic and secreted forms [22]. Xiao, et al. detected the Ig kappa V and Ig alpha $\mathrm{C}$ regions in serum-free conditioned medium from primary lung cancer cells [23]. Cancer-associated Ig shared some characteristics with normal Ig produced by B lymphocytes, but differed with respect to genetic processing [24, 25], transcription [26], expression [25], protein structure [27], post-translational modification [27] and biological function [28-31]. These results suggested that aberrant Ig-like molecule expression might represent a common feature of malignant epithelial cells. These Iglike molecules are reflected in blood and urine and may contribute to cancer occurrence and progression. IGKC, Ig kappa chain V-IV region Len, protein IGKV2-28, and Ig lambda-2 chain $\mathrm{C}$ regions have not, to our knowledge, been previously associated with lung cancer.

AAT is a serine protease inhibitor synthesized primarily in liver, but also in extra-hepatic tissues and cells, including tumor cells. AAT overexpression has been observed in patients with various tumors, including lung cancer $[32,33]$. Plasma AAT levels are reportedly elevated in lung cancer patients [34-36]. AAT is required for cancer cell migration, invasion, and pericellular fibronectin assembly [37]. The C-terminal fragment of AAT induced tumor cell proliferation and invasiveness in human pancreatic adenocarcinoma [38], melanoma [39] and breast carcinoma cells [40]. In contrast, AAT downregulation by short hairpin RNA (shRNA) suppressed cell proliferation, metastasis, and adhesion in human lung adenocarcinoma A549 cells and in the lung 

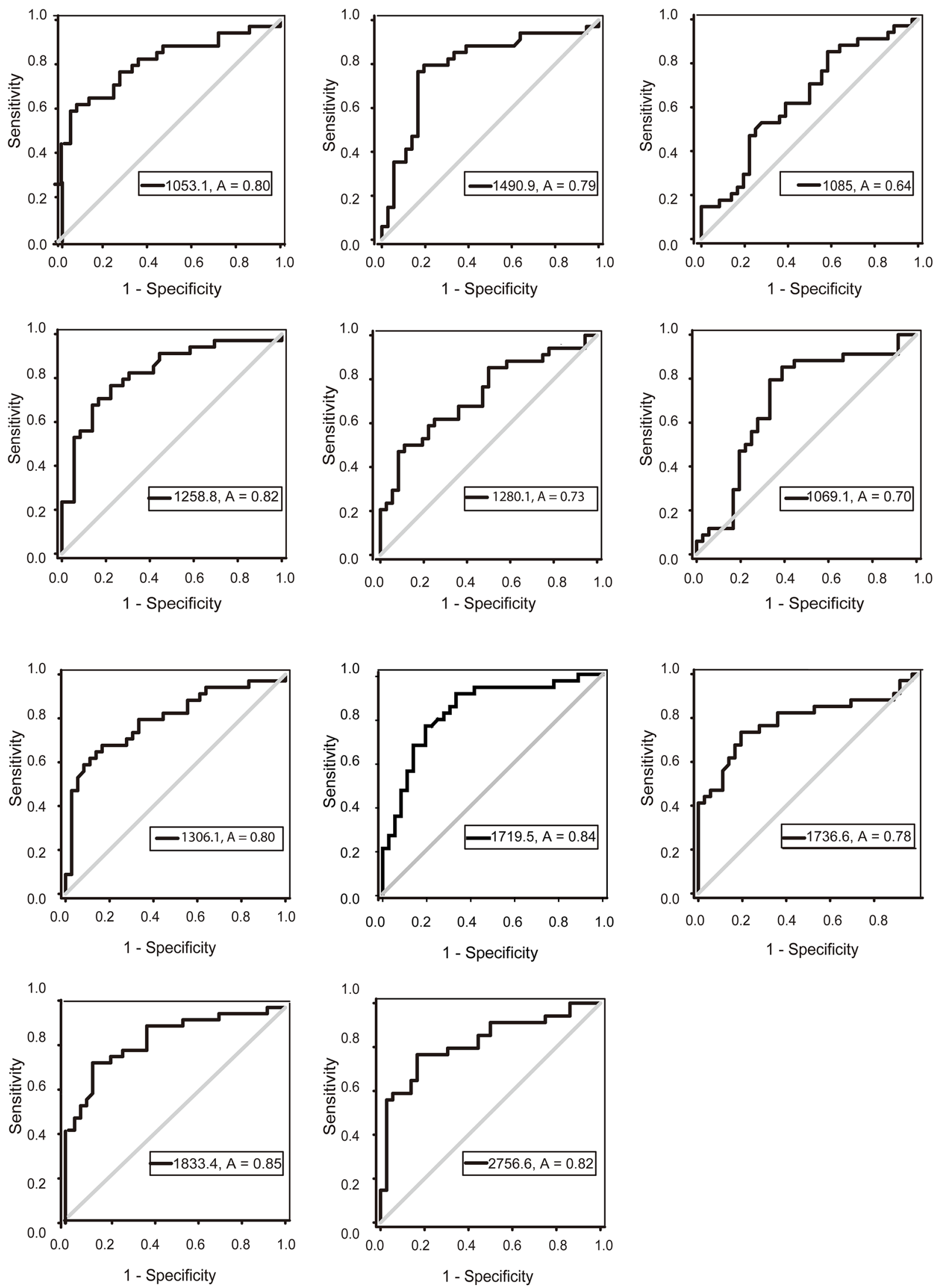

Figure 5: ROC curves of potential urine biomarker levels for differentiating LAC from the normal control. The AUCs of $\mathrm{m} / \mathrm{z} 1053.1,1258.8,1490.9,1306.1,1719.5,1833.4,2756.6$ were $0.81,0.83,0.80,0.80,0.84,0.86,0.82$. The AUCs of $\mathrm{m} / \mathrm{z} 1069.1,1085$, $1280.1,1736.6$ were $0.70,0.64,0.73,0.79$, respectively. 
Table 2: Identified peptides sequence of the selected peaks

\begin{tabular}{|c|c|c|c|c|}
\hline $\begin{array}{l}\text { Swiss-Prot } \\
\text { Acc. No. }\end{array}$ & $\mathbf{m} / \mathbf{z}$ & $\begin{array}{l}\text { Molecular } \\
\text { weight }\end{array}$ & peptide sequences & Protein name \\
\hline A0A087X130 & 1053.1 & 1052.5 & LNNFYPRE & Ig kappa chain $\mathrm{C}$ region(IGKC) \\
\hline P01009 & 1490.9 & 1494.7 & FGDTEEAKKQIND & Alpha-1-antitrypsin \\
\hline P01625 & 1280.1 & 1276.6 & DIVMTQSPDSLA & Kappa chain V-IV region Len \\
\hline Q5T123 & 1085 & 1086.5 & YSTSVTGSRE & $\begin{array}{l}\text { SH3 domain-binding glutamic acid-fat- } \\
\text { like protein } 3 \text { (SH3BGRL3) }\end{array}$ \\
\hline A0A087X1V9 & 1258.8 & 1258.7 & YLQKPGQSPQL & Protein IGKV2-28 \\
\hline P01009 & 1306.1 & 1307.7 & MIEQNTKSPLF & Alpha-1-antitrypsin \\
\hline Q5T123 & 1719.5 & 1719.9 & LAGNPKATPPQIVNGDQ & $\begin{array}{l}\text { SH3 domain-binding glutamic acid- } \\
\text { rich-like protein } 3 \text { (SH3BGRL3) }\end{array}$ \\
\hline P01040 & 1736.6 & 1736.9 & IPGGLSEAKPATPEIQE & Cystatin-A \\
\hline P10451 & 1833.4 & 1833.9 & ESEELNGAYKAIPVAQD & Osteopontin \\
\hline Q5T0H9 & 2756.6 & 2759.4 & TAQLDEELGGTPVQSRVVQGKEPAHL & Gelsolin \\
\hline Q5T0H9 & 1097.8 & 1096.6 & FVLKTPSAAY & Gelsolin \\
\hline \multirow[t]{2}{*}{ D6RBV2 } & 1296.2 & 1297.5 & LDTYPNDETTE & $\begin{array}{l}\text { Vesicular integral-membrane protein } \\
\text { VIP3(LMAN2) }\end{array}$ \\
\hline & 1069.1 & & & Identification failure \\
\hline
\end{tabular}

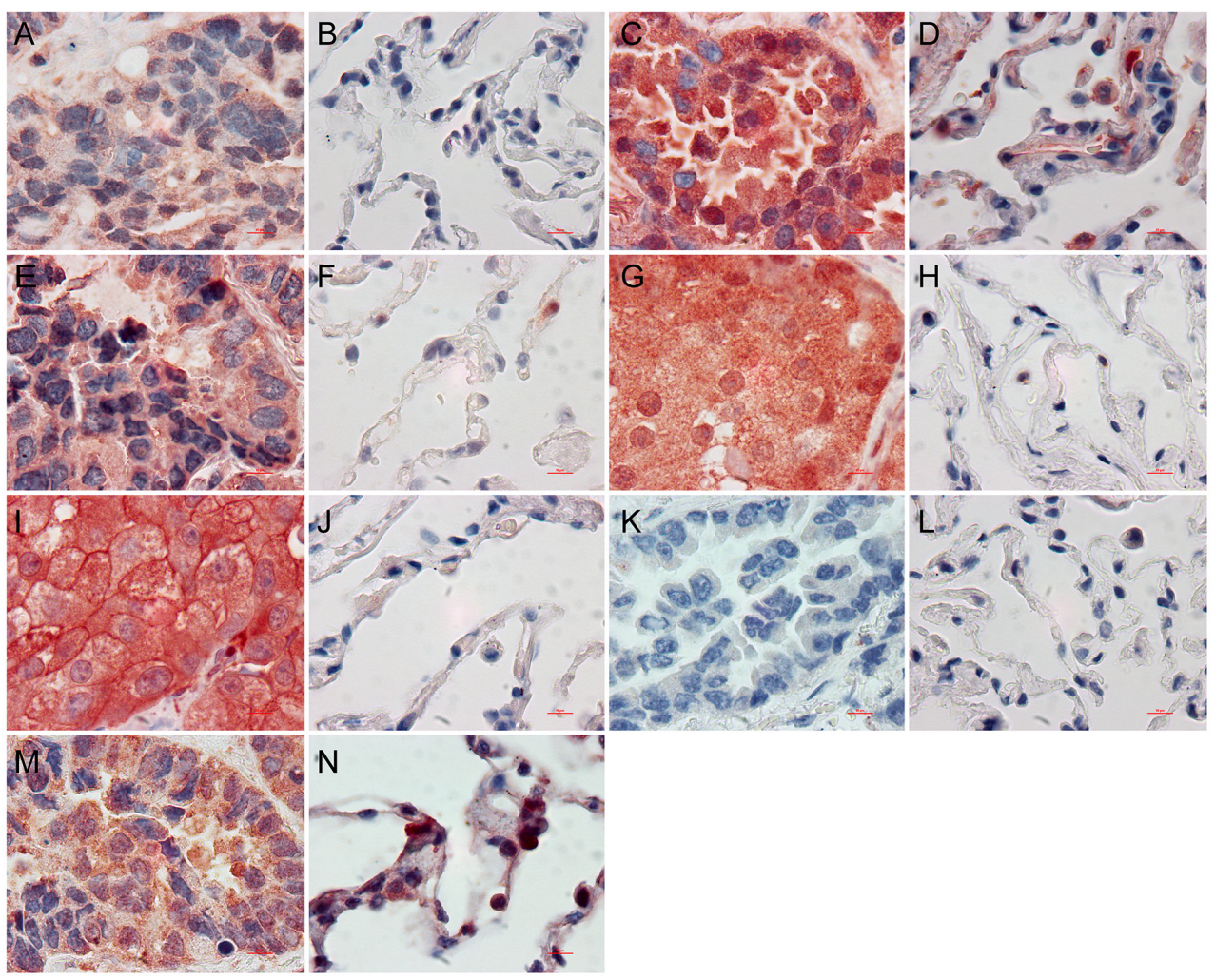

Figure 6: The expression of proteins using immunohistochemistry assay. IGKC A. AAT C. SH3BGRL3 E. osteopontin G. gelsolin I. in LAC tissues were significantly different with IGKC B. AAT D. SH3BGRL3 F. osteopontin H. gelsolin J. in normal lung tissues, respectively. Cystain-A was negative in LAC K. and adjacent normal lung tissue L. LMAN2 was positive in LAC M. and adjacent normal lung tissue N. $(\times 1000)$. 
Table 3: The expressions of IGKC, AAT, SH3BGRL3, osteopontin, gelsolin, cystain-A and LMAN2 in LACs and adjacent normal lung tissues

\begin{tabular}{lcccccc}
\hline Proteins & \multicolumn{2}{c}{ LAC $(\boldsymbol{n}=\mathbf{2 0})$} & & Normal lung tissue $(\boldsymbol{n}=\mathbf{2 0})$ & & $\boldsymbol{P}$ \\
\cline { 2 - 3 } \cline { 6 - 7 } & $\mathbf{4 - 1 2}$ & $\mathbf{0 - 3}$ & & $\mathbf{4 - 1 2}$ & $\mathbf{0 - 3}$ & \\
\hline IGKC & 5 & 15 & & 0 & 20 & 0.047 \\
AAT & 7 & 13 & & 1 & 19 & 0.044 \\
SH3BGRL3 & 9 & 11 & & 2 & 18 & 0.031 \\
osteopontin & 7 & 13 & & 1 & 19 & 0.044 \\
gelsolin & 7 & 13 & & 1 & 19 & 0.044 \\
cystain-A & 2 & 18 & & 0 & 20 & 0.487 \\
LMAN2 & 9 & 11 & & 3 & 17 & 0.273 \\
\hline
\end{tabular}

Table 4: Demographics of patients and normal control subjects

\begin{tabular}{|c|c|c|c|c|}
\hline & \multicolumn{2}{|c|}{ Urine set } & \multicolumn{2}{|c|}{ Tissue set } \\
\hline & $\begin{array}{l}\text { Cancer } \\
\text { patient } \\
(n=34)\end{array}$ & $\begin{array}{l}\text { Normal } \\
\text { control } \\
(n=36)\end{array}$ & $P$ & $\begin{array}{c}\text { Tumor/adjacent } \\
\text { normal pairs } \\
(n=20)\end{array}$ \\
\hline Age & $62.6 \pm 11.1$ & $62.3 \pm 10.6$ & $P=0.52$ & $65.4 \pm 9.8$ \\
\hline \multicolumn{5}{|l|}{ Gender } \\
\hline Female & $14(41 \%)$ & $15(42 \%)$ & $P=0.98$ & $8(40 \%)$ \\
\hline Male & $20(59 \%)$ & $21(58 \%)$ & & $12(60 \%)$ \\
\hline \multicolumn{5}{|l|}{ Smoking habit } \\
\hline Nonsmoker & $22(65 \%)$ & $23(64 \%)$ & $P=0.94$ & $12(60 \%)$ \\
\hline Ever smoker & $12(35 \%)$ & $13(36 \%)$ & & $8(40 \%)$ \\
\hline \multicolumn{5}{|l|}{ Clinical stage } \\
\hline I-II & 14 & & & 8 \\
\hline III-IV & 20 & & & 12 \\
\hline
\end{tabular}

tissues of a K-rasLA1 mouse model [32]. On the other hand, AAT deficiency may increase lung cancer risk [41]. Still, AAT-positive adenocarcinomas are associated with worse prognoses as compared to AAT-negative tumors [33]. Our results demonstrated that AAT peptides in LAC patients urines differed from those in normal controls. The AAT protein was elevated in lung cancer tissues, suggesting that AAT might play promote carcinogenesis in vivo, in addition to its role as proteinase inhibitor. Importantly, AAT peptides in urine might be potential LAC biomarkers.

SH3BGRL3 is a member of the SH3BGR protein family, but lacks the typical SH3- and Homer EVH1binding motifs, suggesting a function different from that of other subfamily members [42]. SH3BGRL3 was upregulated in glioblastoma multiformand primary bladder cancers as compared to non-tumor tissues, and was detected inurothelial carcinoma patient urine
[43, 44]. SH3BGRL3 appears to promote cancer cell proliferation, epithelial-mesenchymal transition (EMT), and cell migration. We found that SH3BGRL3 interacts with epidermal growth factor receptor (EGFR) at Y1068, Y1086, and Y1173 through Grb2 via its proline-rich motif,and activates the Akt-associated signaling pathway [44]. This protein had not been previously associated with lung cancer. Our results demonstrated that SH3BGRL3 peptides distinguished LAC patient urine from normal control samples.

In conclusion, our study identified urine peptides closely associated with LAC, and measurement of these peptides in urine using WCX-MALDI-TOF may specifically detect LAC. These biomarkers must be validated in larger numbers of urine samples from additional lung cancer patients. At present, the biomarkers identified here have not been applied clinically due in part to the high costs and statistical processing requirements 
Table 5: The characteristic of antibodies

\begin{tabular}{|c|c|c|c|c|}
\hline Antibody name & Species reactivity & Clonality & dilution & manufacturers \\
\hline $\begin{array}{l}\text { anti-Ig kappa chain } \mathrm{C} \text { region (IGKC) } \\
\text { antibody }\end{array}$ & mouse anti-human & monoclonal & $1: 200$ & Abcam, UK \\
\hline anti-alpha 1 antitrypsin antibody & mouse anti-human & monoclonal & $1: 300$ & Abcam, UK \\
\hline $\begin{array}{l}\text { anti-SH3 domain-binding glutamic acid- } \\
\text { fat-like protein } 3 \text { (SH3BGRL3) antibody }\end{array}$ & rabbit anti-human & polyclonal & $1: 100$ & Abcam, UK \\
\hline anti-osteopontin antibody & mouse anti-human & monoclonal & $1: 300$ & Abcam, UK \\
\hline anti-cystain A antibody & mouse anti-human & monoclonal & $1: 50$ & Abcam, UK \\
\hline anti-gelsolin antibody & rabbit anti-human & monoclonal & $1: 400$ & Abcam, UK \\
\hline anti-LMAN2 antibody & rabbit anti-human & polyclonal & $1: 100$ & Abcam, UK \\
\hline
\end{tabular}

of our methods. Therefore, new detection methods and bioinformatics tools are urgently needed for the analysis of low abundance proteins and peptides from body fluids.

\section{MATERIALS AND METHODS}

\section{Study subjects}

This research was approved by the ethics committee of Beijing Shijitan Hospital, Capital Medical University (research ethics review No. 5, 2014). Patients with LAC and healthy individuals were recruited from Beijing Shijitan Hospital from October 2014 until December 2015, following a clinical check of renal function and urinary sediment at the same medical facility. All parcitipants provided written informed consent in accordance with the provisions of the Helsinki Declaration. All LAC patients were pathologically diagnosed by two senior pathologists. Thirty-six healthy individuals were recruited from a healthy public population cohort (Beijing, China) undergoing annual medical examination in Beijing Shijitan Hospital. LAC patients and healthy individuals characteristics are provided in Table 4. No urine samples exhibited hematuresis and urinary albumin/creatinine ratios $(\mathrm{A} / \mathrm{Cr})$ were $<30 \mathrm{mg} / \mathrm{g}$. We also utilized $20 \mathrm{LAC}$ and adjacent nontumor tissue pairs, of which 20 were a subset of the tissue set. Adjacent normal tissues were at least 5 $\mathrm{cm}$ distant from the tumor. Individuals excluded from the study if they had received preoperative chemotherapy or radiotherapy. LAC patients were separated according to the 2009 TNM classification of malignant tumors by the International Union Against Cancer and the American Joint Committee on Cancer.

\section{Urine collection}

Midstream urine samples $(50 \mathrm{ml})$ were collected by sterile polypropylene tubes in the morning and were immediately centrifuged at $400 \mathrm{~g}$ for $15 \mathrm{~min}$ to remove cell debris and casts. Supernatants were divided into aliquots and stored at $-80^{\circ} \mathrm{C}$.

\section{Fractionation of urine peptides}

All samples were fractionated by WCX-MB according to the manufacture's instructions (Bruker Daltonics). Samples were purified and separated through binding, washing and elution. First, $10 \mu \mathrm{l}$ MB-WCX, 95 $\mu \mathrm{WCX}-\mathrm{MB}$ binding solution and $10 \mu \mathrm{l}$ urine were mixed thoroughly in a polypropylene tube, and then incubated for 5 min. Tubes were placed in the magnetic bead separation device (Bruker Daltonics) for 1 min to separate the unboud solution. Magnetic beads were then washed three times with $100 \mu$ magnetic bead washing solution. Second, 10 $\mu \mathrm{l}$ MB-WCX elution solution was added to the beads and mixed by vortexing. Finally, the supernatant was transferred into a fresh tube. $5 \mu \mathrm{MB}$-WCX stabilizing solution was added. The well-mixed eluate was then stored at $-20^{\circ} \mathrm{C}$.

\section{MALDI-TOF-MS and data processing}

Urine sample eluates were diluted 1:10 in matrix solution containing $\alpha$-cyano-4-hydroxycinnamic acid (Bruker Daltonics). Then, $1 \mu$ of the resulting mixture was spotted onto the AnchorChip target (Bruker Daltonics), allowed to air dry, and ionized by a nitrogen laser $(\lambda=337$ $\mathrm{nm}$ ) operating at $25 \mathrm{~Hz}$. MALDI-TOF MS was performed using an Autoflex TOF instrument (Bruker Daltonics). Three standard peptides were used as an external standard preparation to ensure the average molecular weight deviation was no more than 100 ppm. For data processing, all spectra obtained from urine samples were analyzed using BioExplorer ${ }^{\mathrm{TM}}$ software (Bioyong Tech, Beijing, China). Each spectrum was normalized using total ion count. Peak $\mathrm{m} / \mathrm{z}$ values or intensities in the 1000-10000 Da range from all signals with a signal-tonoise ratio $>5$ were determined. To align the spectra, a mass shift of no more than $0.1 \%$ was determined. Peaks 
that were detected in $>80 \%$ of samples were considered informative. The $\mathrm{t}$ test was applied to compare the peak volumes in the two groups. Peaks with adjusted $p$ values $<$ 0.05 and average peak intensities $>300$ were regarded as statistically significant. Peak area was used as quantitative standardization. Thenceforth, the RBF algorithm was used to find the best pattern for distinguishing LAC.

\section{Peptide biomarkers identifications}

Identification of differentially expressed peptides sequences was performed using a nano-LC/ESI-MS/ MS system consisting of an Aquity Ultra Performance LC (UPLC) system (Waters, USA) and an LTQ Orbitrap MS(Thermo Scientific, Germany) equipped with a nanoESI source. Desalted peptides were analyzed using a C18 analytical column $(75 \mathrm{um} \times 500 \mathrm{~mm}, 100 \AA$ Magic, $2 \mu \mathrm{m})$ at a flow rate of $300 \mathrm{nl} / \mathrm{min}$ with the mobile phases A (5\% acetonitrile, $0.1 \%$ formic acid, Sigma-Aldrich, USA) and B (95\% acetonitrile, $0.1 \%$ formic acid). The gradient elution profile was as follows: 5\%B-5\%B-30\%B-90\%B-5\%B over $60 \mathrm{~min}$. The MS instrument was operated in a datadependent model. Proteome Discoverer (PD) version 1.4 (Thermo -Scientific) was used to search against with the Uniprot-SwissProt Human protein database for the raw data files. The search engine Mascot (version 2.3.2) was implemented in PD as per the manufacturer's instructions. Downloaded files were searched directly using Mascot through PD. The search parameters were as follows: 50 ppm tolerance for precursor ion masses, $0.8 \mathrm{Da}$ for fragment ion mass tolerance, a false discovery rate (FDR) ance,no enzymes, no fixed modification and variable modification.

\section{Immunohistochemistry}

LAC and adjacent non-tumor tissues obtained during surgery were fixed in $10 \%$ formalin, embedded in paraffin, and sectioned into 4-mm slices. Slides were deparaffinized for 20 minutes in xylene and then dehydrated in 100\%, $100 \%, 95 \%$, and $75 \%$ alcohol, for 2 minutes at each concentration. After five 10-min rinses in phosphatebuffered saline (PBS), antigen retrieval was performed by heating slides in a pressure cooker with antigen unmasking solution. Slides were then washed with PBS for $10 \mathrm{~min}$, incubated for $15 \mathrm{~min}$ in $3 \% \mathrm{H}_{2} \mathrm{O}_{2}$, and rinsed again with PBS for $10 \mathrm{~min}$. After antigen retrieval, samples were incubated at $4{ }^{\circ} \mathrm{C}$ overnight with antibodies respectively (the antibodies were listed in Table 5). Samples were then washed with PBS, incubated with horseradish peroxidaseconjugated secondary antibody (Beijing Zhongshan Jinqiao Biotechnology, Beijing, China) for $20 \mathrm{~min}$ at $37^{\circ} \mathrm{C}$ and then washed again with PBS for $15 \mathrm{~min}$. Samples were stained using chromogen 3,3'-diaminobenzidine solution (Beijing Zhongshan Jinqiao Biotechnology, China) for $5 \mathrm{~min}$, counterstained with hematoxylin for $2 \mathrm{~min}$, dehydrated with $75 \%, 95 \%, 100 \%$, and $100 \%$ alcohol, cleaned with xylene, and sealed with natural gum.
Immunostaining was blindly evaluated by two independent experienced pathologists using a light microscope (Nikon Ci-S, Japan). Images were captured using NIS Elements F software (Nikon). The scoring method was described previously [45], Using at least 10 randomly selected high-power fields. Each specimen was scored according to staining intensity (intensity) and area (extent). Staining intensity was scored as follows: "0", no staining; "1", mild staining; "2", moderate staining and " 3 ", intense staining. The percentage of positive cells was divided into five categories, " 0 ", no staining; " 1 ", 1-10\%; "2", 11-50\%; “3”, 51-80\%; “4”, 81-100\%. Staining intensity and percentage were multiplied to produce a total score. A total score of 4-12 was defined as positive expression, and 0-3 was considered negative.

\section{Statistical analysis}

SPSS software 22.0 was used to calculate all statistical comparisons. A $t$-test (normally distributed continuous data) or Mann-Whiney $U$ test (nonnormally distributed continuous data) was employed to compare polypeptide levels between LAC and normal control groups. The area under the curve (AUC) of the receiver operating characteristic (ROC) curve was used to assessed specificity and sensitivity for each biomarker. Chi-squared tests were used to assess baseline characteristic differences between LAC and control groups and to compare proteins levels in LACs and adjacent normal lung tissues. All tests were two-sided, and $P<0.05$ was considered significant.

\section{ACKNOWLEDGMENTS}

We are grateful to all volunteers whose urine and tissue donations made this study possible.

\section{CONFLICTS OF INTEREST}

The authors declare no conflicts of interest.

\section{GRANT SUPPORT}

This work was supported by the Beijing Municipal Administration of Hospitals' Ascent Plan (Code: DFL20150701) and the National High Technology Research and Development Program (863 Program) (2014AA022304).

\section{REFERENCES}

1. Siegel RL, Miller KD, Jemal A. Cancer statistics, 2016. CA Cancer J Clin. 2016; 66:7-30.

2. Langer CJ, Besse B, Gualberto A, Brambilla E, Soria JC. The evolving role of histology in the management of 
advanced non-small-cell lung cancer. Journal of clinical oncology. 2010; 28:5311-5320.

3. Torre LA, Siegel RL, Jemal A. Lung Cancer Statistics. Advances in experimental medicine and biology. 2016; 893:1-19.

4. Brenner DJ. Radiation risks potentially associated with low-dose CT screening of adult smokers for lung cancer. Radiology. 2004; 231:440-445.

5. Uribarri M, Hormaeche I, Zalacain R, Lopez-Vivanco G, Martinez A, Nagore D, Ruiz-Arguello MB. A new biomarker panel in bronchoalveolar lavage for an improved lung cancer diagnosis. Journal of thoracic oncology. 2014; 9:1504-1512.

6. Chinello C, Cazzaniga M, De Sio G, Smith AJ, Grasso A, Rocco B, Signorini S, Grasso M, Bosari S, Zoppis I, Mauri G, Magni F. Tumor size, stage and grade alterations of urinary peptidome in RCC. Journal of translational medicine. 2015; 13:332.

7. Halder S, Dey RK, Chowdhury AR, Bhattacharyya P, Chakrabarti A. Differential regulation of urine proteins in urothelial neoplasm. Journal of proteomics. 2015; 127:185-192.

8. Kumar P, N i S, Tan TZ, Ler SG, Chia KS, Lim WY, Butow Z, Vordos D, De la Taille A, Al-Haddawi M, Raida M, Beyer B, Ricci E, Colombel M, Chong TW, Chiong E, et al. Highly sensitive and specific novel biomarkers for the diagnosis of transitional bladder carcinoma. Oncotarget. 2015; 6:13539-13549.

9. Metzger J, Negm AA, Plentz RR, Weismuller TJ, Wedemeyer J, Karlsen TH, Dakna M, Mullen W, Mischak H, Manns MP, Lankisch TO. Urine proteomic analysis differentiates cholangiocarcinoma from primary sclerosing cholangitis and other benign biliary disorders. Gut. 2013; 62:122-130.

10. Radon TP, Massat NJ, Jones R, Alrawashdeh W, Dumartin L, Ennis D, Duffy SW, Kocher HM, Pereira SP, Guarner posthumous L, Murta-Nascimento C, Real FX, Malats N, et al. Identification of a Three-Biomarker Panel in Urine for Early Detection of Pancreatic Adenocarcinoma. Clinical cancer research. 2015; 21:3512-3521.

11. Zhang M, Fu G, Lei T. Two urinary peptides associated closely with type 2 diabetes mellitus. PloS one. 2015; 10:e0122950.

12. Jia K, Li W, Wang F, Qu H, Qiao Y, Zhou L, Sun Y, Ma Q, Zhao X. Novel circulating peptide biomarkers for esophageal squamous cell carcinoma revealed by a magnetic bead-based MALDI-TOFMS assay. Oncotarget. 2016; 7:23569-23580. doi: 10.18632/oncotarget. 8123.

13. Zhang H, Cao J, Li L, Liu Y, Zhao H, Li N, Li B, Zhang A, Huang H, Chen S, Dong M, Yu L, Zhang J, Chen L. Identification of urine protein biomarkers with the potential for early detection of lung cancer. Scientific reports. 2015; $5: 11805$.

14. Ray S, Reddy PJ, Jain R, Gollapalli K, Moiyadi A, Srivastava S. Proteomic technologies for the identification of disease biomarkers in serum: advances and challenges ahead. Proteomics. 2011; 11:2139-2161.

15. Marimuthu A, O'Meally RN, Chaerkady R, Subbannayya Y, Nanjappa V, Kumar P, Kelkar DS, Pinto SM, Sharma R, Renuse S, Goel R, Christopher R, Delanghe B, et al. A comprehensive map of the human urinary proteome. Journal of proteome research. 2011; 10:2734-2743.

16. Pedroza-Diaz J, Rothlisberger S. Advances in urinary protein biomarkers for urogenital and non-urogenital pathologies. Biochemia medica. 2015; 25:22-35.

17. Lin Q, Guo L, Lin G, Chen Z, Chen T, Lin J, Zhang B, Gu $\mathrm{X}$. Clinical and prognostic significance of OPN and VEGF expression in patients with non-small-cell lung cancer. Cancer epidemiology. 2015; 39:539-544.

18. Jin Y, Tong DY, Tang LY, Chen JN, Zhou J, Feng ZY, Shao CK. Expressions of Osteopontin (OPN), alphanubeta3 and Pim-1 Associated with Poor Prognosis in Non-small Cell Lung Cancer (NSCLC). Chinese journal of cancer research. 2012; 24:103-108.

19. Yang J, Tan D, Asch HL, Swede H, Bepler G, Geradts J, Moysich KB. Prognostic significance of gelsolin expression level and variability in non-small cell lung cancer. Lung cancer (Amsterdam, Netherlands). 2004; 46:29-42.

20. Chang YS, Kim HJ, Chang J, Ahn CM, Kim SK, Kim SK. Elevated circulating level of osteopontin is associated with advanced disease state of non-small cell lung cancer. Lung cancer (Amsterdam, Netherlands). 2007; 57:373-380.

21. Rodriguez-Pineiro AM, Blanco-Prieto S, Sanchez-Otero $\mathrm{N}$, Rodriguez-Berrocal FJ, de la Cadena MP. On the identification of biomarkers for non-small cell lung cancer in serum and pleural effusion. Journal of proteomics. 2010; 73:1511-1522.

22. Qiu X, Zhu X, Zhang L, Mao Y, Zhang J, Hao P, Li G, Lv P, Li Z, Sun X, Wu L, Zheng J, Deng Y, et al. Human epithelial cancers secrete immunoglobulin $g$ with unidentified specificity to promote growth and survival of tumor cells. Cancer research. 2003; 63:6488-6495.

23. Xiao T, Ying W, Li L, Hu Z, Ma Y, Jiao L, Ma J, Cai Y, Lin D, Guo S, Han N, Di X, Li M, Zhang D, Su K, Yuan J, et al. An approach to studying lung cancer-related proteins in human blood. Molecular \& cellular proteomics. 2005; 4:1480-1486.

24. Cao Y, Sun Y, Poirier S, Winterstein D, Hegamyer G, Seed J, Malin S, Colburn NH. Isolation and partial characterization of a transformation-associated sequence from human nasopharyngeal carcinoma. Molecular carcinogenesis. 1991; 4:297-307.

25. Zheng H, Li M, Ren W, Zeng L, Liu HD, Hu D, Deng X, Tang M, Shi Y, Gong J, Cao Y. Expression and secretion of immunoglobulin alpha heavy chain with diverse VDJ recombinations by human epithelial cancer cells. Molecular immunology. 2007; 44:2221-2227.

26. Li M, Tang M, Deng X. [Positive immunoglobulin A expression in human epithelial carcinoma cell lines]. 
Zhonghua zhong liu za zhi [Chinese journal of oncology]. 2001; 23:451-453.

27. Lee G, Laflamme E, Chien $\mathrm{CH}$, Ting $\mathrm{HH}$. Molecular identity of a pan cancer marker, CA215. Cancer biology \& therapy. 2008; 7:2007-2014.

28. Li M, Feng DY, Ren W, Zheng L, Zheng H, Tang M, Cao Y. Expression of immunoglobulin kappa light chain constant region in abnormal human cervical epithelial cells. The international journal of biochemistry \& cell biology. 2004; 36:2250-2257.

29. Liu HD, Zheng H, Li M, Hu DS, Tang M, Cao Y. Upregulated expression of kappa light chain by EpsteinBarr virus encoded latent membrane protein 1 in nasopharyngeal carcinoma cells via NF-kappaB and AP-1 pathways. Cellular signalling. 2007; 19:419-427.

30. Hu D, Tong S, Wei R, Hui Z, Haidan L, Zhi D, Lili L, Wen T, Dan Z, Yanfeng L, Dongxin L, Ya C. The polymorphisms on Igkappa gene are related to susceptibility of breast cancer and gastric cancer. Genetic testing. 2008; 12:575-580.

31. Ren W, Zheng H, Li M, Deng L, Li XL, Pan KF, Lu YY, Cao Y. A functional single nucleotide polymorphism site detected in nasopharyngeal carcinoma-associated transforming gene Tx. Cancer genetics and cytogenetics. 2005; 157:49-52.

32. Chang SH, Cho KC, Yu KN, Hong SH, Park S, Lee AY, Kim S, Lee S, Kang JW, Chae C, Park J, Kim KP, Cho $\mathrm{MH}$. Alpha 1-antitrypsin activates lung cancer cell survival by acting on cap-dependent protein translation, vesiclemediated transport, and metastasis. Oncotarget. $2016 \mathrm{Jul}$ 19. doi: 10.18632/oncotarget.10695. [Epub ahead of print]

33. Higashiyama M, Doi O, Kodama K, Yokouchi H, Tateishi R. An evaluation of the prognostic significance of alpha-1antitrypsin expression in adenocarcinomas of the lung: an immunohistochemical analysis. British journal of cancer. 1992; 65:300-302.

34. Zelvyte I, Wallmark A, Piitulainen E, Westin U, Janciauskiene S. Increased plasma levels of serine proteinase inhibitors in lung cancer patients. Anticancer research. 2004; 24:241-247.

35. El-Akawi ZJ, Al-Hindawi FK, Bashir NA. Alpha-1 antitrypsin (alpha1-AT) plasma levels in lung, prostate and breast cancer patients. Neuro endocrinology letters. 2008; 29:482-484.

36. El-Akawi ZJ, Abu-Awad AM, Sharara AM, Khader Y. The importance of alpha-1 antitrypsin (alpha1-AT) and neopterin serum levels in the evaluation of non-small cell lung and prostate cancer patients. Neuro endocrinology letters. 2010; 31:113-116.

37. Chang YH, Lee SH, Liao IC, Huang SH, Cheng HC, Liao PC. Secretomic analysis identifies alpha-1 antitrypsin (A1AT) as a required protein in cancer cell migration, invasion, and pericellular fibronectin assembly for facilitating lung colonization of lung adenocarcinoma cells. Molecular \& cellular proteomics. 2012; 11:1320-1339.

38. Kataoka H, Uchino H, Iwamura T, Seiki M, Nabeshima $\mathrm{K}$, Koono M. Enhanced tumor growth and invasiveness in vivo by a carboxyl-terminal fragment of alpha1-proteinase inhibitor generated by matrix metalloproteinases: a possible modulatory role in natural killer cytotoxicity. The American journal of pathology. 1999; 154:457-468.

39. Zelvyte I, Sjogren HO, Janciauskiene S. Effects of native and cleaved forms of alpha1-antitrypsin on ME 1477 tumor cell functional activity. Cancer detection and prevention. 2002; 26:256-265.

40. Zelvyte I, Lindgren S, Janciauskiene S. Multiple effects of alpha1-antitrypsin on breast carcinoma MDA-MB 468 cell growth and invasiveness. European journal of cancer prevention. 2003; 12:117-124.

41. Yang P, Sun Z, Krowka MJ, Aubry MC, Bamlet WR, Wampfler JA, Thibodeau SN, Katzmann JA, Allen MS, Midthun DE, Marks RS, de Andrade M. Alpha1-antitrypsin deficiency carriers, tobacco smoke, chronic obstructive pulmonary disease, and lung cancer risk. Archives of internal medicine. 2008; 168:1097-1103.

42. Majid SM, Liss AS, You M, Bose HR. The suppression of SH3BGRL is important for v-Rel-mediated transformation. Oncogene. 2006; 25:756-768.

43. Khalil AA. Biomarker discovery: a proteomic approach for brain cancer profiling. Cancer science. 2007; 98:201-213.

44. Chiang CY, Pan CC, Chang HY, Lai MD, Tzai TS, Tsai YS, Ling P, Liu HS, Lee BF, Cheng HL, Ho CL, Chen SH, Chow NH. SH3BGRL3 Protein as a Potential Prognostic Biomarker for Urothelial Carcinoma: A Novel Binding Partner of Epidermal Growth Factor Receptor. Clinical Cancer Research. 2015; 21:5601-5611.

45. Yu S, Meng Q, Hu H, Zhang M. Correlation of ANXA1 expression with drug resistance and relapse in bladder cancer. International journal of clinical and experimental pathology. 2014; 7:5538-55. 